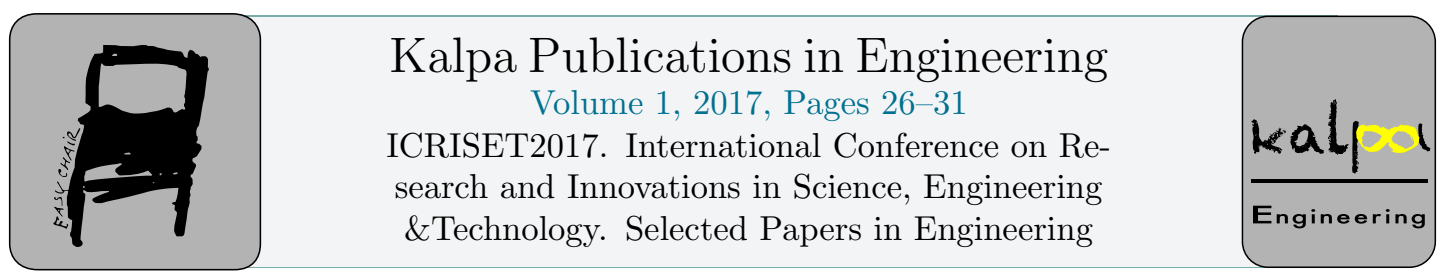

\title{
Solar Based Electronic Fences with Wireless Informant
}

\author{
Bhoomika Bilodariya ${ }^{1}$, Pankaj Ramchandani ${ }^{2}$ and Dr. D.L.Vala ${ }^{3}$ \\ Electronics Engineering, BVM Engineering College \\ Vallabh Vidhyanagar, Gujarat, India \\ bhoomi_rajput0110@yahoo.in, pankajawsm@gmail.com,dlvala@bvmengineering.ac.in
}

\begin{abstract}
Solar based electronic fences use the principle of converting solar energy into electrical energy and giving electronic shock while touching the fences. Electronic fences are used at many places such as forest area, farm, government area etc. to protect them against animals and thefts. It consists of small components which used to convert solar energy to electrical and further will convert $\mathrm{DC}$ voltage to $\mathrm{AC}$ voltage and provide shock to the person who is touching the fences. The solar energy is converted to the electrical energy which is in the form of unregulated DC voltage. This unregulated DC voltage is converted to the regulated DC voltage and further converted to the AC voltage using inverter. This inverted high $\mathrm{AC}$ voltage and small current helps to give short but sharp shock so animals and thefts stay away from that area. The change in current is sensed and gives alert to the owner. Owner will know who is entering in the farm by the device IR sensor which senses the entry of the person.
\end{abstract}

\section{Introduction}

Fences referred to as the device which protects the area by building them surround the area. Solar based electronic fence is the electronic device which gives sharp but safe shock to the person who is touching the fences. Basically the idea behind designing this project is give protection to the particular area against the thefts and animals. The area includes some government areas, forest lands, farms etc. The device consists of the components such as solar panel, regulator, inverter, transformer etc. The solar energy from the sun is converted to the electrical energy which is in the form of unregulated DC voltage. This unregulated DC voltage is regulated using the regulator. This DC voltage is converted to the $\mathrm{AC}$ voltage using the device called inverter. Inverter gives $\mathrm{AC}$ signal which has higher voltage and very low current which is sufficient to give shock to the person. 
Now the owner has to know that anyone had touched the fences. For that we have solution that when the person touches the fences, small amount of current will change that will sensed by the sensor and the indication will transmitted to the owner by using the wireless protocol.

Now the additional facility to the owner of the area is that when anyone enters from the main gate he/she will capture by the IR sensor and owner will know that anyone has entered into their area by means of wireless protocol Wi-Fi.

The wireless protocol used in this design is Wi-Fi module ESP8266 which is used to send data from controller to the user's device. We are using IoT technology for wireless transmission where controller used is Arduino UNO.

\section{Problem statement}

The main reason behind this design is to provide security in addition with safety that touches the fences. It provides sharp but safe shock to the animal or thefts that are touching the fences.

\section{Basic Data Flow Diagram}

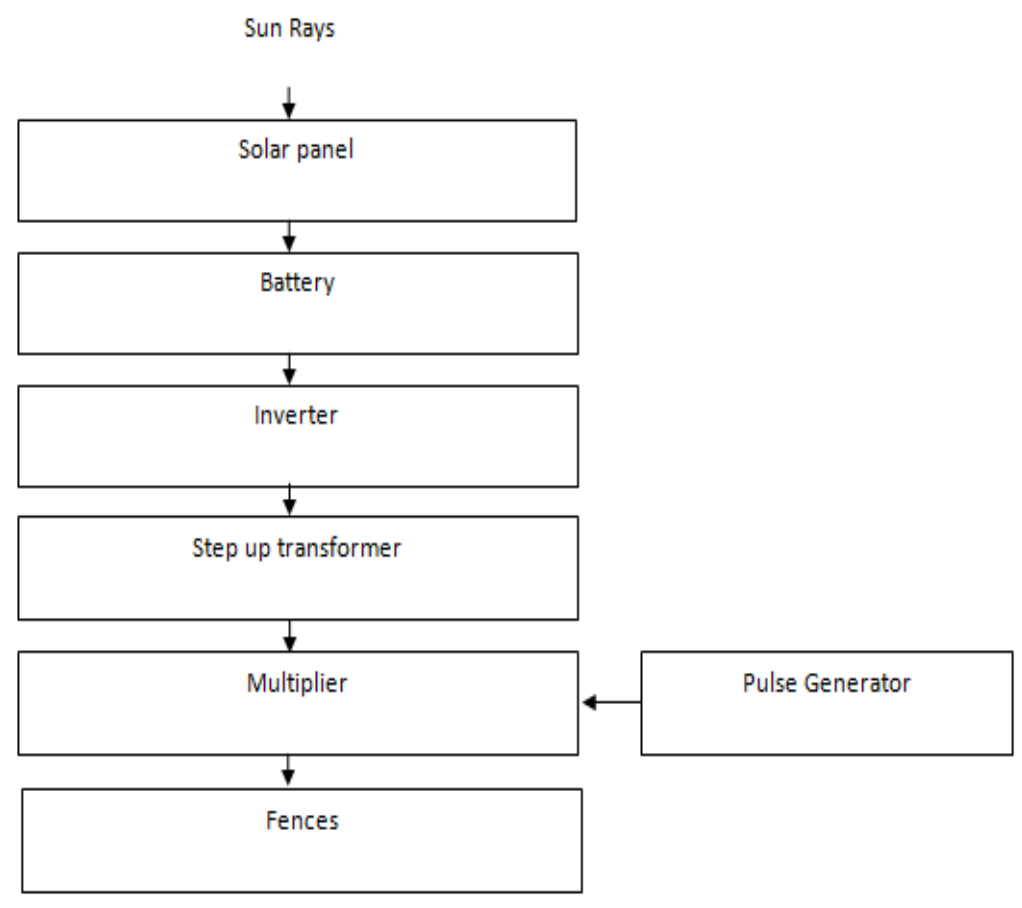

Figure 1: Basic Data flow Diagram 


\section{System Design}

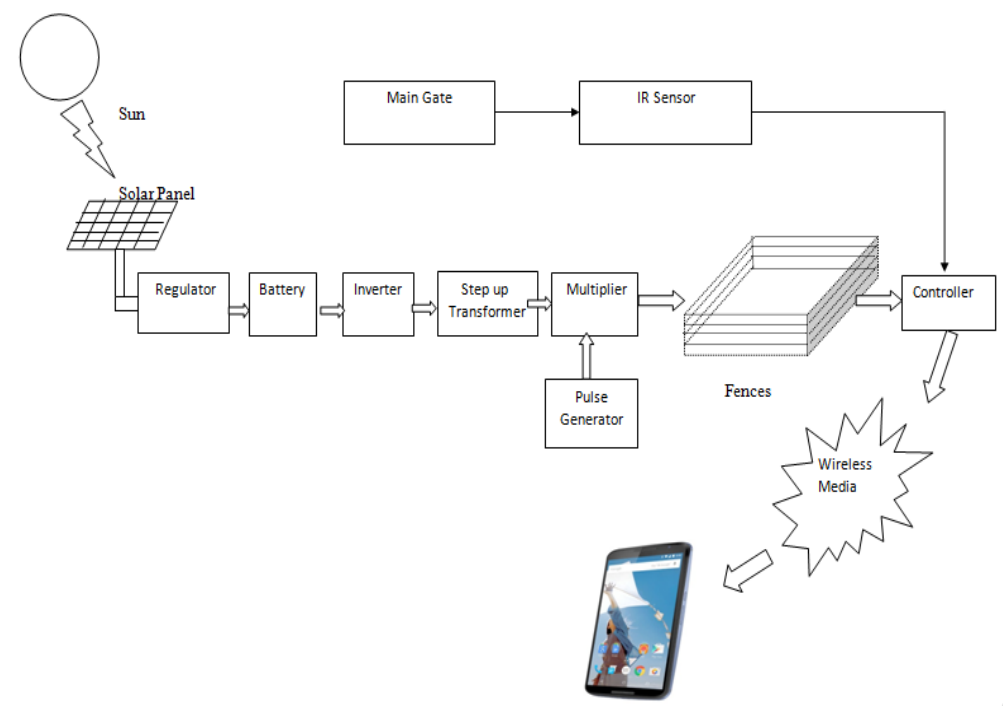

Figure 2: Basic system design

\section{Modules}

\section{Solar system:}

In this project the solar system works as the energy supplier. It converts the solar energy into the electrical energy by means of solar panel. Solar panel is made of photovoltaic cell which works as transducer.

\section{Regulator:}

The converted electrical energy from the solar system is in the form of unregulated DC voltage. But we required the regulated DC voltage. To regulate the electrical supply we need the regulator which gives regulated DC voltage from unregulated DC voltage.

3. Inverter:

To give the safe shock we need AC signal so that person will immediately can be out of the contact of the fences. Inverter gives AC signal at the output when we are giving DC signal to the input.

\section{Pulse generator:}

This module provides the pulse signal whose duty cycle is changing as per the requirement. It must be selected such that nobody gets harmed. In this the duty cycle is $33 \%$ where on time is $0.5 \mathrm{~s}$ and off time is $1 \mathrm{~s}$.

The duty cycle of the pulse generator can be change by changing the value of resistors by using the equation 


$$
\text { Ton }=0.69(\mathrm{R} 1+\mathrm{R} 2) \mathrm{C}
$$

Toff $=0.69 \mathrm{R} 2 * \mathrm{C}$

\section{Multiplier:}

The output from the inverter is continuous AC signal. But we required discrete signal so that the current will flow through the fences at the finite interval. Multiplier does this work. There are two inputs to the multiplier, one is the signal from inverter and another is from the pulse generator with required duty cycle.

\section{Controller:}

Owner of the area has know whether anyone gets touches the fences or not. To do that there is some mechanism that gives indication to the owner. When anyone comes in contact with fences, small amount of current will change and will detected by the controller and will transmitted to the owner's device by means of wireless protocol that is $\mathrm{Wi}-\mathrm{Fi}$.

7. Wi-Fi: Wi-Fi module ESP8266 we are using in this project for communication purpose. That change in current is detected by the controller with respect to the reference set by user and by the use of serial transmission with ESP8266 wi-Fi module we inform about this changes to our user.

\section{Circuit Design}

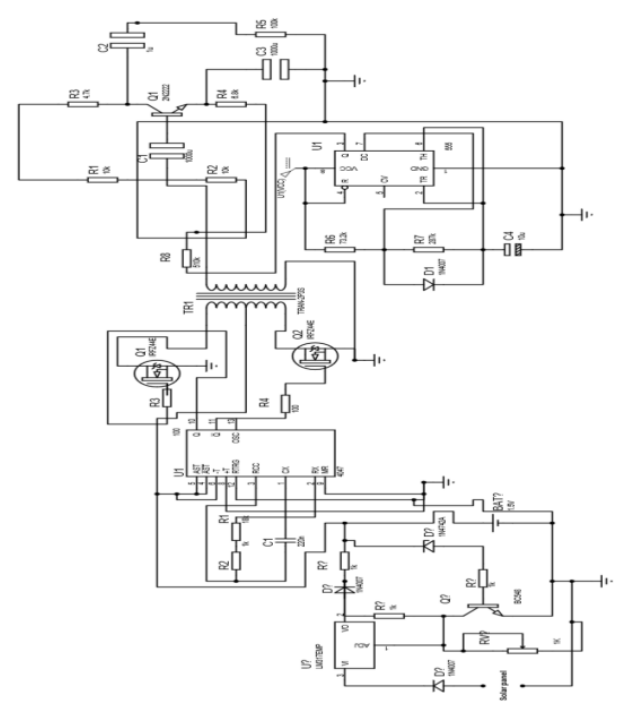

Figure 3: Circuit design 


\section{Simulation Results}

\section{Pulse generator}

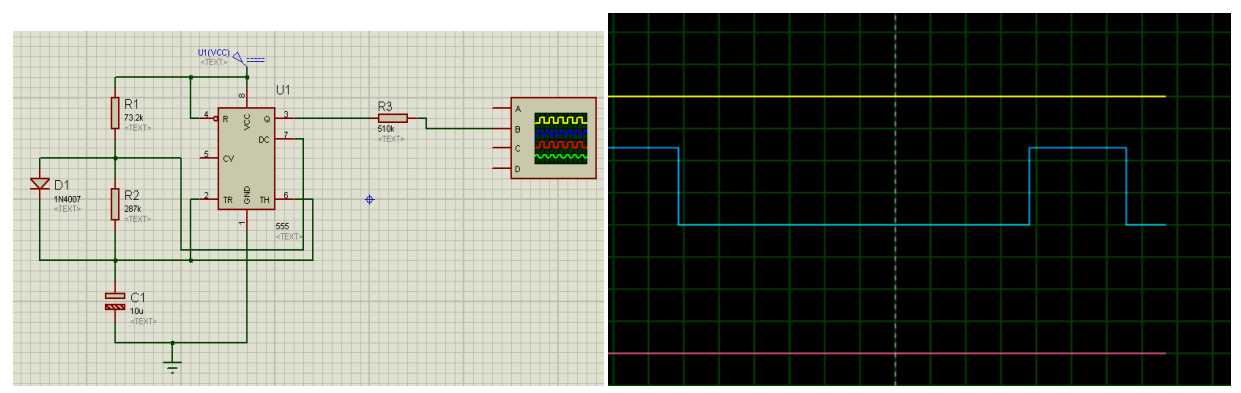

Figure 4: Pulse Generator

\section{Inverter}

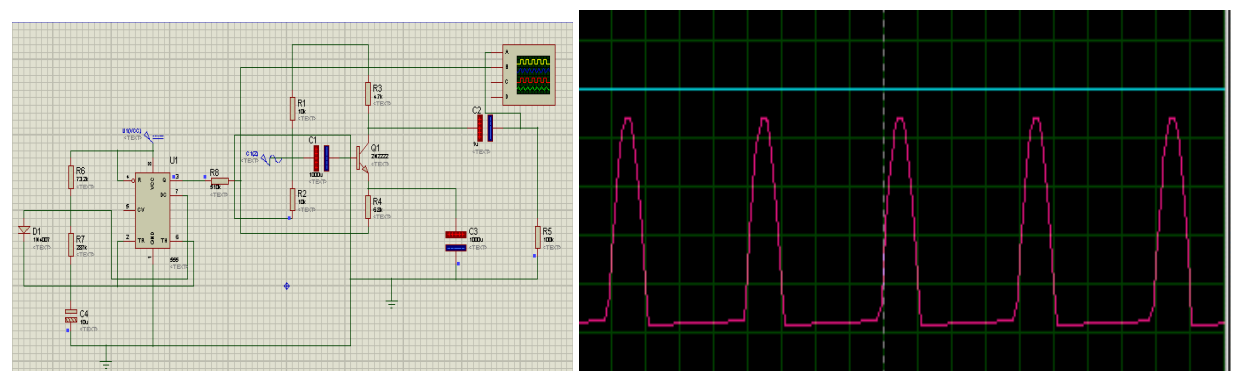

Figure 5: Inverter

\section{Advantages:}

- Designed to work on solar energy and hence independent of grid power

- Significantly reduces man-animal conflicts

- Effective wildlife management tool for park managers

- Cost effective

- Can be installed easily

\section{Applications:}

- Electric fence systems have varied application in Agriculture, Industrial and Forestry or Plantation sectors.

- With increasing crime in urban areas, this proven technology has now been adapted for domestic security applications too.

- Industrial: Security Electric Fence systems provide 100\% protections against theft, sabotage.

- The fence systems can also be integrated with other security devices like sirens, flood lights etc. 
- Domestic: The wall top system for residential applications is attractive and ideal for compounds, rooftops, farm houses and apartments.

\section{Conclusions}

Generally electronic fences provides analog signal at the fences. But in this the output signal is PWM signal so that if someone touches the fences that will not be in contact for more time. Solar based electronic fences give accurate output as it has digital signal. It reduces the electricity as we used the solar system at the power supply. This is safe to the human being and also to the animals as we applied discrete current to the fences. At output the current is in very small amount and voltage is very high as to give sharp and safe shock. This system is reliable as an owner will know whenever anyone gets touches the fences and whenever anyone get enter into the area.

\section{Acknowledgements}

We would like to express our best regards to our project guide Dr. Deepak L. Vala for their valuable guidance, encouragement and provision of necessary knowledge which carries our design success.

We are very grateful to our HOD. Dr. Tanmay D. Pawar whose help and shared knowledge was very helpful to make our project successful. Many thanks owed to our friends for their useful discussion and timely suggestions. Their technical support and encouragement helped us for this project.

\section{References}

1 Chang, P-F., L-Y. Chu, and Y-K. Wu. "A non-lethal high-voltage intelligent intrusion sensor." Security Technology, 1991. Proceedings. 25th Annual 1991 IEEE International Carnahan Conference on. IEEE, 1991.

2 Wei, Chunjuan, et al. "A design of alarm system for substation perimeter based on laser fence and wireless communication." International conference on computer application and system modeling (ICCASM). Vol. 3. 2010.

3 Fernando, Marcelo Giovanni B. De Martino, and S. dos Reis Guilherme AD Dias. "AN ELECTRIC FENCE ENERGIZER DESIGN METHOD."

4 Monod, M. O., et al. "A virtual fence for animals management in rangelands."MELECON 2008-The 14th IEEE Mediterranean Electrotechnical Conference. IEEE, 2008. 